\title{
Biodynamics of cholesterol and bile acids in the lithiasic hamster
}

\author{
BY J. KHALLOU, M. RIOTTOT, M. PARQUET, C. VERNEAU AND C. LUTTON \\ Laboratoire de Physiologie de la Nutrition, URA 0646 CNRS, Bât. 447, Université Paris-Sud, \\ 91405 Orsay Cedex, France
}

(Received 11 September 1990 - Accepted 25 February 1991)

\begin{abstract}
By using the isotopic equilibrium method in the young male Syrian hamster, the rates of cholesterol turnover processes, i.e. dietary cholesterol absorption, cholesterol synthesis, cholesterol excretion in the faeces and urine and cholesterol transformation into bile acids, were determined in the hamster receiving a control (C) or a lithogenic diet (L) for 7 weeks. At the end of this period the gall bladder of all animals in group $\mathbf{L}$ contained cholesterol gallstones. The coefficient of dietary cholesterol absorption was reduced by $26 \%$, cholesterol synthesis and cholesterol faecal excretion were twofold higher in group $L$ than in group $\mathrm{C}$. Bile acid content in the small intestine was diminished in group $\mathrm{L}$, but bile acid composition was similar in the two groups. The increase in cholesterogenesis in lithiasic animals essentially took place in the liver. Bile acid biosynthesis did not significantly differ in the two groups, but represented only $35 \%$ of total cholesterol input (dietary absorption + internal secretion) in group $L v$. $52 \%$ in group $C$. Thus, in the lithiasic hamster, hepatic synthesis of cholesterol and bile acids are not coupled. The molar percentage of cholesterol in bile was twofold higher in group $\mathrm{L}$ than in group $\mathrm{C}$ but those of bile acids and of phospholipids were not modified. In the lithiasic hamster the specific activity of biliary cholesterol was similar to that in plasma and liver. Consequently, biliary cholesterol does not derive directly from cholesterol newly synthesized in the liver but from hepatic cholesterol rapidly exchangeable with plasma cholesterol.
\end{abstract}

Lithiasis: Cholesterol: Bile acids: Gallstones: Hamster

Cholesterol gallstones were induced in young golden Syrian hamsters maintained on a high-sucrose fat-free diet (Dam, 1969). The mechanisms of gallstone formation in this animal model are not fully understood but seem to be associated with an increase in hepatic cholesterol synthesis (Ginsberg et al. 1977; Turley \& Spady, 1983) and biliary cholesterol secretion (Robins \& Fasulo, 1973; Wheeler, 1973). In patients with cholesterol gallstones, alterations of these two mechanisms have also been observed (Salen et al. 1975; Reuben et al. 1985). Other mechanisms of cholesterol metabolism and particularly changes in cholesterol turnover processes induced by a fat-free diet in the hamster might explain gallstone formation. These turnover processes of cholesterol, i.e. the input (absorption and synthesis) and the output (faecal cholesterol and bile acid excretion) studied by an isotopic equilibrium method have not been documented in this animal (Lutton, 1990). In man and the hamster the role of the liver in endogenous cholesterol synthesis has been well described (Salen et al. 1975; Ginsberg et al. 1977), but the extent to which extrahepatic sterol synthesis was affected under this nutritional condition remained unclear. Moreover, in the lithiasic hamster, it is also not clear whether the increase in biliary cholesterol secretion is related to the transport of larger quantities of hepatic newly-synthesized sterol in the bile.

In man gallstone formation is occasionally associated with a change in biliary bile acid composition (Alvaro et al. 1985). In hamsters in which cholelithiasis is induced by a fat-free diet this point is controversial. Singhal et al. (1984) observed no modification in 
composition but Ginsberg et al. (1977) showed an increase in the proportion of chenodeoxycholic acid. This point warrants clarification.

In the present work, the use of an isotopic equilibrium method for determination of rates of cholesterol turnover processes during the growth of hamsters was validated. Indeed, this method has been validated in many experimental conditions in the adult rat (Mathe \& Lutton, 1984) and also during growth of this animal (Chevallier, 1964; Chevallier \& Giraud, 1966) or the increase in cholesterol in the liver (Lutton \& Chevallier, 1972) but not in the young hamster, a new animal model for this study. Then a detailed study of the rates of the cholesterol turnover processes in lithiasic hamsters compared with control hamsters was undertaken. In these two groups of animals, the contribution of the different organs to sterol synthesis in the body was estimated by the measurement of the $\left[1-{ }^{14} \mathrm{C}\right]$ acetate incorporation into digitonin-precipitable sterols. The role of the liver was also determined by the measurement of the activity of microsomal hydroxymethylglutaryl-CoA (HMG$\mathrm{CoA})$ reductase $(E C 1.1 .1 .88)$. At the isotopic equilibrium of cholesterol, the origin of cholesterol secreted in the bile and of that precipitated in the gall bladder was estimated by the determination of the specific activity of cholesterol in the bile and in gallstones. Thus, if biliary cholesterol is derived preferentially from the newly-synthesized cholesterol, its specific activity must be lower than those of the plasma and the liver. Moreover, the effect of the lithogenic diet on biliary lipids and biliary bile acid composition was measured. In control and lithiasic hamsters, the quantities and the composition of bile acids in the gastrointestinal tract were also measured in order to determine whether intestinal cholesterol absorption was associated with a modification of these two variables.

\section{MATERIALS AND METHODS}

\section{Animals}

Young male Golden Syrian hamsters were purchased from the specialized breeding unit of CNRS, Villejuif (France). The animals were 6 weeks old and weighed 55.4 (SE 1.1) g at the beginning of the experiments. Food and water were provided ad lib. throughout the 7 weeks of the study. The room temperature was maintained at $23 \pm 1^{\circ}$ and lighting conditions were controlled according to a $12 \mathrm{~h}$ cycle.

Control animals were fed on a semi-purified diet (basal diet) containing $(\mathrm{g} / \mathrm{kg})$ : sucrose 528 , lactic casein 230 , skim milk 40 , lard 92 , walnut oil 8 , yeast 25 , vitamin mix on agar 25 , mineral mix 50 , cystine 2 , cholesterol 0.5 . Lithiasic animals were fed on the lithogenic diet described by Dam (1969) in which $0.5 \mathrm{~g}$ cholesterol $/ \mathrm{kg}$ was added. This diet contained $(\mathrm{g} / \mathrm{kg})$ : sucrose 725 , lactic casein 200 , mineral mix 50 , vitamin mix on agar 25 , cholesterol 0.5 . The compositions of the mineral and vitamin mixtures used in these diets were those described by Rukaj \& Sérougne (1983).

\section{Determination of cholesterol turnover rates in vivo}

Cholesterol turnover rates (absorption, biosynthesis, urinary and faecal excretion and transformation of cholesterol into bile acids) were measured using the isotopic equilibrium method (Chevallier \& Lutton, 1966; Lutton \& Chevallier, 1972). Control ( $n 9)$ and lithiasic ( $n$ 9) hamsters were fed on the diets labelled with trace amounts of $\left[4-{ }^{14} \mathrm{C}\right]$ cholesterol $(370 \mathrm{kBq} / \mathrm{kg}$ diet) for 7 weeks. Simultaneously they received a daily subcutaneous injection of $\left[1,2-{ }^{3} \mathrm{H}\right]$ cholesterol $(0 \cdot 1 \mathrm{mg}, 18 \mathrm{kBq} / \mathrm{d}$ per hamster $)$. To verify the establishment of isotopic equilibrium of cholesterol in those animals, one hamster per group was killed at the end of the first, second, third and fifth weeks of experiment and the specific activity of their plasma cholesterol was measured. The dietary consumption and total faecal radioactivity eliminated weekly were determined during the last 3 weeks of the experiment. 
When the isotopic equilibrium of cholesterol is achieved, the specific activity of plasma cholesterol remains constant and the input and output of the radioactivity of the marker from the body are the same. At the end of the seventh week, the remaining non-fasting hamsters (five hamsters per group) were killed at 10.00 hours by aortic puncture after Tiletamine-Zolazepam (Virbac, France) anaesthesia. The cardiovascular system was washed three times with physiological saline $(9 \mathrm{~g}$ sodium chloride/1). Plasma, liver, small intestine, caecum and colon, faeces and urine were collected and stored in ethanol. Lipids from the organs, urine and faeces were extracted with ethanol for $24 \mathrm{~h}$ in a Soxhlet apparatus, while the plasma lipids were extracted for $30 \mathrm{~min}$. Free and esterified cholesterol from plasma and liver were separated by silica-gel thin-layer chromatography. All lipid fractions (i.e. extracts from Soxhlet and free and esterified cholesterol from silica gel) were saponified in boiling ethanolic $2 \mathrm{M}$-potassium hydroxide for $2.5 \mathrm{~h}$, the sterols were extracted with light petroleum (b.p. 35- $60^{\circ}$ ). Plasma and liver cholesterol was precipitated with digitonin and assayed using the Lieberman-Burchard reaction. After extraction of neutral steroids, bile acids were deconjugated by the method of Grundy et al. (1965) in intestinal contents and faeces, and by the enzyme choloylglycine hydrolase (EC 3.5.1.24) in gall bladder bile. Free bile acids were methylated with diazomethane, silylated with Deriva-Sil (Chrompack, the Netherlands) and assayed on a Carlo Erba HRGC 5160 chromatograph equipped with a standard fused silica WCOT capillary column cross-linked with $0 \mathrm{~V} 1701$ (length $25 \mathrm{~m}, 0.2 \mu \mathrm{m}$ film thickness). Oven temperature was $240^{\circ}$ and the flow-rate of the carrier gas hydrogen was $2 \mathrm{ml} / \mathrm{min}$. The bile acid content of gall bladder, small intestine and caecum + colon were determined by dividing total activity of the acidic fraction extracted from the contents by the specific activity of plasma cholesterol.

The flows involved in cholesterol turnover, absorption, internal and external secretions excretion and transformation of cholesterol into bile acids were calculated from the radioactivities of neutral faecal sterols and of faecal bile acids and from the specific radioactivities of dietary cholesterol and of plasma cholesterol (Lutton \& Chevallier, 1972). Thus, flows were calculated as follows: absorption $m_{A}=m_{l}-m_{N A}$, where $m_{N A}$ represents non-absorption and $m_{I}$ represents ingestion; $m_{N A}=R_{N A} / r_{l}$, where $R_{N A}$ is the radioactivity of non-absorbed cholesterol and $r_{I}$ is the specific radioactivity of dietary cholesterol; $R_{N A}=$ $R_{F^{\prime} 1}-R_{F E}$, where $R_{F_{1}}$ and $R_{F E}$ are the ${ }^{14} \mathrm{C}$ radioactivities of neutral sterols and excreted cholesterol respectively in the faeces; $R_{F E}=m_{F_{E}} \times r_{p l}$, where $r_{p t}$ is ${ }^{14} \mathrm{C}$ radioactivity of plasma cholesterol and $m_{F E}$ is faecally excreted cholesterol; $m_{F^{\prime} E}=R_{F^{2} 2} / r_{p 2}$ where $R_{F^{2} 2}$ and $r_{p 2}$ are the ${ }^{3} \mathrm{H}$ radioactivities of neutral faecal sterols and specific radioactivity of plasma cholesterol respectively; external secretion $m_{E S}=m_{F}-m_{N A}-m_{F E}$, where $m_{F}$ is the total faecal cholesterol; $m_{F}=R_{F} / r_{F}$, where $R_{F}$ and $r_{F}$ are the total and specific radioactivities $\left({ }^{3} \mathrm{H}\right.$ or $\left.{ }^{14} \mathrm{C}\right)$ respectively of faecal neutral sterols; transformation into bile acids $m_{T}=R_{a c} / r_{p l}$, where $R_{a c}$ is the ${ }^{14} \mathrm{C}$ radioactivity of faecal acidic fraction; internal secretion $m_{I S}=m_{A}^{\prime}\left(r_{l}-r_{p I}\right) / r_{I}$ where $m_{A}^{\prime}=m_{A}$ ((radioactive outputs $) /($ radioactive inputs $\left.)\right) \times 100$; total synthesis $m_{S}=m_{I S}+m_{E S}$; absorption coefficient $=\left(m_{A} / m_{I}\right) \times 100$. The flow of endogenous cholesterol or internal secretion corresponds to input into plasma of cholesterol synthesized in the organs. The external secretion represents elimination in the faeces of cholesterol synthesized in the digestive tract. The total synthesis of cholesterol is the sum of internal and external secretions. The excretion is represented by elimination in the faeces of cholesterol of plasma origin.

\section{Determination of sterol synthesis rates in vivo}

To determine organs involved in cholesterol synthesis in the body, control ( $n 5)$ and lithiasic (n 5) hamsters received a subcutaneous injection of $37 \mathrm{MBq}\left[1-{ }^{14} \mathrm{C}\right]$ acetate at 10.00 hours and were killed $70 \mathrm{~min}$ later. After washing the cardiovascular system with a saline 
solution, liver, small intestine, caecum, colon, spleen, adrenals and kidneys were collected. The intestines were gently washed with cold saline solution. These organs were boiled in $2 \mathrm{M}-\mathrm{KOH}$ for $2 \cdot 5 \mathrm{~h}$. Sterols were extracted with light petroleum (b.p. $35-60^{\circ}$ ) precipitated with digitonin and their radioactivity was assayed.

\section{Determination of hepatic $H M G-C o A$ reductase activity}

Control ( $n$ 5) and lithiasic ( $n$ 5) hamsters were killed and the livers were immediately removed, chilled and sliced: $1 \mathrm{~g}$ of these slices was poured into cold saline buffer $(50 \mathrm{~mm}-$ Tris, $0 \cdot 3 \mathrm{M}-\mathrm{D}(+)$ sucrose, $10 \mathrm{~mm}$-dithiothreitol, $10 \mathrm{~mm}$-EDTA, $50 \mathrm{~mm}-\mathrm{NaCl}, \mathrm{pH} \mathrm{7.4})$. Microsomes were prepared by the method of Einarsson et al. (1986) and immediately frozen in liquid nitrogen and stored at $-70^{\circ}$. Enzyme activity was stable for at least 3 months in this form (Alberts et al. 1980). The total microsomal HMG-CoA reductase activity was measured by the method of Rodwell et al. (1976).

\section{Biliary lipid assays}

The common bile duct was catheterized with a PE10 polyethylene tube ( $\mathrm{n}^{\circ}$. 105, Biotrol, France) after cystic duct ligation with 0000 black silk, and hepatic bile was collected for $1 \mathrm{~h}$ in five control and five lithiasic hamsters. At the end of this period, the animals were killed and the gall bladder was removed. Cholesterol content of washed gallstones and biliary cholesterol were measured by means of commercial reagent kits (Boehring, Mannheim; Roda et al. 1975). Total bile acids were quantified using the $3 \alpha$-hydroxysteroid dehydrogenase (EC 1.1.1.50) method described by Turley \& Dietschy (1978). Phospholipids were assayed with a commercial kit (Wako, Dardilly, France; Gurantz et al. 1981). Lithogenic index was calculated according to Thomas \& Hofmann (1973) and to Carey (1978). This index is determined by the ratio, percentage of cholesterol in the sample: percentage of cholesterol theoretically soluble in the sample. Two classical methods were used to calculate this index and will be further discussed. According to Thomas \& Hofmann (1973) maximal solubility of cholesterol in the sample is a polynomial function of the ratio, phospholipid:phospholipid + bile acid expressed as a molar percentage. According to Carey (1978) maximal solubility of cholesterol in mixed micelles for a wide range of total lipid concentration is determined using model biles and critical tables have been established.

\section{Measurement of radioactivity}

The radioactivities of all samples were measured in a PPO (dimethyl 2,5-diphenyloxazole)POPOP (2,2'-p-phenyl oxazole toluene) solution with a liquid-scintillation spectrometer (MR 300 Kontron).

\section{RESULTS}

\section{Physiological state of hamsters}

The growth of lithiasic and control hamsters during the 7 weeks of the experiment were similar and plateaued at week 13 (Fig. 1). At the end of the feeding period, the body-weight, food intake and weight of faeces were not different for lithiasic and control hamsters (Table 1). The gall bladders of all hamsters in group L contained cholesterol gallstones $(n 40)$ while those of animals in group $\mathrm{C}$ had no gallstones. The gallstone cholesterol content was 0.65 (SE 0.05 ) $\mathrm{mg}$ per gall bladder ( $n$ 40).

The concentration of plasma-free cholesterol did not differ between the two groups but that of esterified cholesterol was slightly decreased in group L compared with group C. Free and esterified cholesterol concentrations in the liver were not significantly different between the two groups (Table 2). 


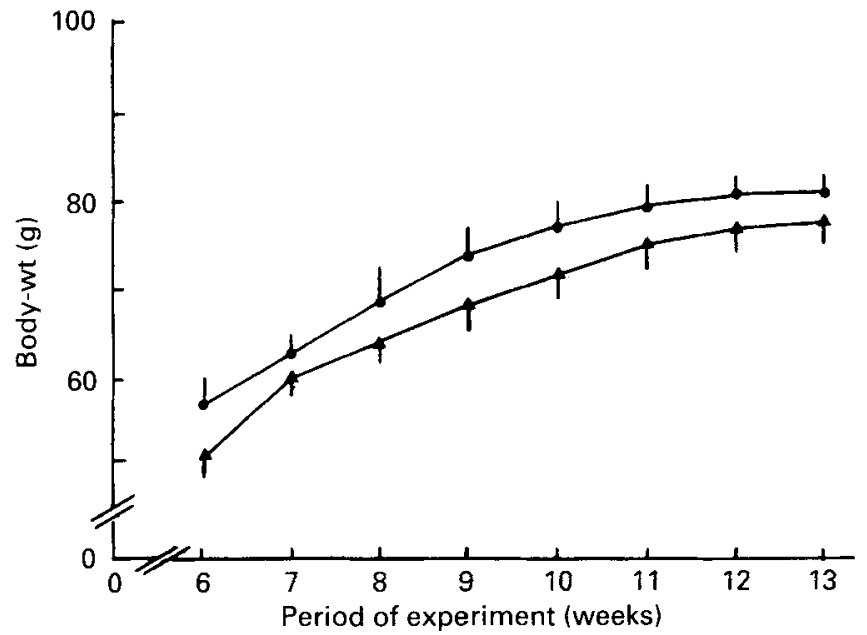

Fig. 1. Growth of control (O) and lithiasic (A) hamster during the experimental period. Values are means with their standard errors of the means, represented by vertical bars, for five hamsters. For details of dietary regimen, see p. 480 .

Table 1. Body-weight, food intake and faeces weight in control $(C)$ and lithiasic hamsters $(L)^{*}$

(Values are means with their standard errors of the means for forty hamsters)

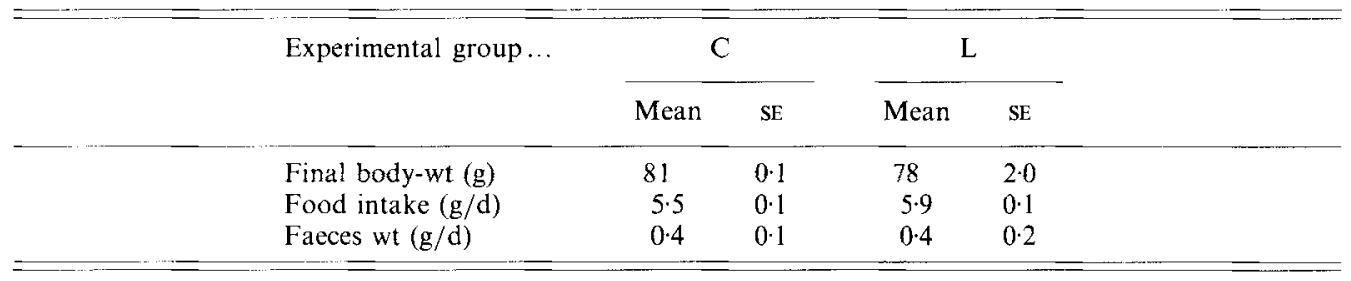

* For details of dietary regimen, see p. 480 .

\section{Validation of isotopic equilibrium of cholesterol}

During the isotope experiment, the specific activity of plasma $\left[{ }^{14} \mathrm{C}\right]$ cholesterol increased with time and reached a plateau after the 3rd to 5th week of experiment in both lithiasic and control hamsters (Fig. 2). During this period gallstones were observed in the gall bladder of the hamster killed at the end of the 3rd week. The total radioactivity of $\left[{ }^{14} \mathrm{C}\right]$ cholesterol eliminated in the faeces each week reached $84-94 \%$ of $\left[{ }^{14} \mathrm{C}\right]$ cholesterol input at the 7 th week of the experiment in these two groups (Table 3), showing that isotopic equilibrium was obtained in lithiasic and control hamsters. Thus, all rates of cholesterol turnover processes were determined at the 7 th week of the isotope experiment, the period in which isotopic equilibrium was established and the body-weight of hamsters remained relatively constant (Fig. 1).

\section{Rates of cholesterol turnover processes}

The coefficient of intestinal cholesterol absorption was significantly lower in group $\mathrm{L}$ than in group $\mathrm{C}$ (Table 4). Consequently, the absorption rate of dietary cholesterol in the first group represented only $50 \%$ of that observed in the second group of animals. Internal cholesterol secretion as well as total synthesis (sum of internal and external secretions) was 
Table 2. Concentration of free $(F)$ and esterified $(E)$ cholesterol of plasma and liver in control $(C)$ and lithiasic hamsters $(L) \dagger$

(Values are means with their standard errors of the means for five hamsters)

\begin{tabular}{|c|c|c|c|c|}
\hline \multirow[t]{2}{*}{ Experimental group... } & \multicolumn{2}{|c|}{$\mathrm{C}$} & \multicolumn{2}{|c|}{$\mathbf{L}$} \\
\hline & Mean & $\mathrm{SE}$ & Mean & SE: \\
\hline \multicolumn{5}{|l|}{ Plasma $(\mathrm{mg} / \mathrm{ml})$} \\
\hline $\mathrm{F}$ & 0.5 & 0.07 & 0.4 & 0.01 \\
\hline $\mathrm{E}$ & 10 & 0.01 & $0.8^{*}$ & 0.03 \\
\hline \multicolumn{5}{|l|}{ Liver (mg/g) } \\
\hline $\mathrm{F}$ & $2 \cdot 8$ & $0 \cdot 08$ & $2 \cdot 9$ & 0.05 \\
\hline $\mathrm{E}$ & $5 \cdot 3$ & $1 \cdot 10$ & $2 \cdot 9$ & $0 \cdot 30$ \\
\hline
\end{tabular}

Mean value was significantly different from that for group $\mathrm{C}$ (Student's $t$ test) : ${ }^{*} P<0 \cdot 05$.

$\dagger$ For details of dietary regimen, see p. 480.

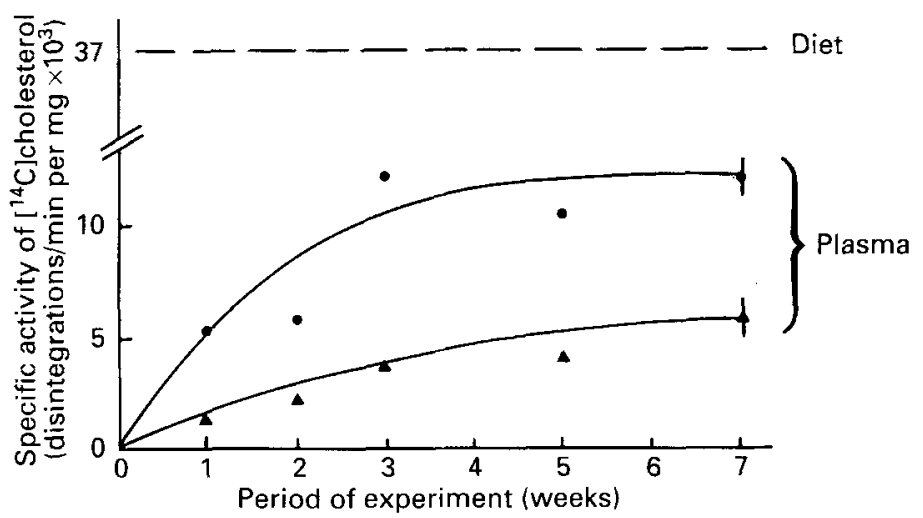

Fig. 2. Evolution of specific activity of plasma cholesterol during the experimental period in control (O) and lithiasic $(\boldsymbol{\Delta})$ hamsters. In the 7 th week, values are means with their standard errors of the means, represented by vertical bars, for five hamsters. For details of dietary regimen, see p. 480.

Table 3. Total radioactivity of $\left[{ }^{14} \mathrm{C}\right]$ cholesterol ingested in the diet (cholesterol input) and the ratio of $\left[{ }^{14} C\right]$ cholesterol output to $\left[{ }^{14} C\right]$ cholesterol input in control $(C)$ and lithiasic (L) hamsters*

(Values are means with their standard errors of the means for five hamsters)

\begin{tabular}{|c|c|c|c|c|}
\hline \multirow[t]{2}{*}{ Experimental group... } & \multicolumn{2}{|c|}{$\mathrm{C}$} & \multicolumn{2}{|c|}{$\mathrm{L}$} \\
\hline & Mean & $\mathrm{SE}$ & Mean & $\mathrm{SE}$ \\
\hline $\begin{array}{l}{\left[{ }^{1 \mathrm{~A}} \mathrm{C}\right] \mathrm{cholesterol} \text { input }} \\
(\mathrm{dpm} / \text { week) }\end{array}$ & 830822 & 1615 & 846577 & 4100 \\
\hline$\frac{\left[{ }^{14} \mathrm{C}\right] \text { cholesterol output }}{\left[{ }^{14} \mathrm{C}\right] \text { cholesterol input }}(\%):$ & & & & \\
\hline week 5 & 66 & 1.8 & 81 & 4 \\
\hline week 6 & 63 & $2 \cdot 9$ & 82 & 5 \\
\hline week 7 & 84 & $2 \cdot 9$ & 94 & $5 \cdot 5$ \\
\hline
\end{tabular}

dpm, Disintegrations/min.

* For details of dietary regimen, see p. 480 . 
Table 4. Intestinal absorption coefficient of dietary cholesterol and flows involved in cholesterol turnover in control $(C)$ and lithiasic $(L)$ hamsters $\dagger$

(Values are means with their standard errors of the means for five hamsters)

\begin{tabular}{|c|c|c|c|c|c|}
\hline & \multirow[t]{2}{*}{ Experimental group ... } & \multicolumn{2}{|c|}{$\mathrm{C}$} & \multicolumn{2}{|c|}{$\mathrm{L}$} \\
\hline & & Mean & SE & Mean & $\mathrm{SE}$ \\
\hline & Absorption coefficient (\%) & $93 \cdot 0$ & $0-8$ & $69 \cdot 00^{* * *}$ & $4 \cdot 3$ \\
\hline & Absorption & $3 \cdot 3$ & 0.06 & $1 \cdot 7 * *$ & 0.07 \\
\hline & Internal secretion & $3 \cdot 8$ & $0 \cdot 3$ & $8 \cdot 4^{* *}$ & $1 \cdot 5$ \\
\hline & External secretion & $0 \cdot 4$ & 0.04 & 0.9 & $0 \cdot 3$ \\
\hline & Faecal excretion & $2 \cdot 6$ & $0 \cdot 2$ & $5 \cdot 4^{* *}$ & $0 \cdot 9$ \\
\hline & Urinary excretion & $0 \cdot 3$ & 0.01 & 0.4 & 0.03 \\
\hline & $\begin{array}{l}\text { Cholesterol } \\
\text { transformation into } \\
\text { bile acids }\end{array}$ & $3 \cdot 7$ & $0 \cdot 1$ & $3 \cdot 6$ & 0.5 \\
\hline & $\begin{array}{l}\text { Coefficient of acidic } \\
\text { transformation of } \\
\text { cholesterol }(\%)\end{array}$ & $52 \cdot 0$ & $1 \cdot 5$ & $35 \cdot 0^{* *}$ & $1 \cdot 2$ \\
\hline
\end{tabular}

Mean values were significantly different from those for group $C$ (Student's $t$ test): ${ }^{* *} P<0.01, * * * P<0.001$.

$\dagger$ For details of dietary regimen, see p. 480 .

$\pm \frac{\text { bile acid synthesis }}{\text { internal secretion }+ \text { absorption of cholesterol }} \times 100$.

twofold higher in group L than in group $\mathrm{C}$. This increase in the rate of cholesterol input was essentially compensated by stimulation of the faecal excretion of cholesterol and of its microbial metabolites. Urinary excretion of cholesterol was not significantly different in the two groups. Transformation of cholesterol into bile acids did not differ significantly in the two groups but represented only 35 (SE 1.2) and 52 (SE 1.5) \% of the total cholesterol input (dietary absorption + internal secretion) respectively in groups $\mathrm{L}$ and $\mathrm{C}$.

\section{Rate of cholesterol synthesis in vivo and in vitro}

These experiments were designed to determine the organs in which cholesterol synthesis was stimulated by experimental cholelithiasis. The incorporation of $\left[1-{ }^{14} \mathrm{C}\right]$ acetate in precipitable sterols from organs of lithiasic and control animals is reported in Table 5. In the small intestine of control hamsters the radioactivity of sterols precipitated by digitonin was twelvefold higher than that of the liver sterols. The in vivo incorporation of $\left[1-{ }^{14} \mathrm{C}\right]$ acetate was also significantly higher in small intestine sterols than that in other organs. In contrast, in the liver of the lithiasic hamster this incorporation was twice as high as that in the small intestine. Furthermore, the sterol radioactivity in the liver was more than thirtyfold higher in the lithiasic hamster than in the control hamster. The sterol radioactivity found in other organs, except for the small intestine and the spleen was not significantly different between the two groups. A complementary experiment indicated that the activity of hepatic HMG-CoA reductase was five times higher in lithiasic animals than in controls (pmol/min per mg protein; C 43 (SE 8) L 202 (SE 26), $n 5$ for each group, $P<0.001)$.

\section{Biliary lipids}

The composition of biliary lipids is given in Table 6 . Molar percentage of biliary cholesterol was twofold higher in group $\mathrm{L}$ than in group $\mathrm{C}$. Molar percentages of phospholipids and bile acids and the concentration of total lipids in the bile were not different between the two 
Table 5. Sterol radioactivity (disintegrations/min) in various organs of control $(C)$ and lithiasic (L) hamsters $70 \mathrm{~min}$ after $100 \mu \mathrm{Ci}\left[1{ }^{14} \mathrm{C}\right]$ acetate subcutaneous injection $\dagger$

(Values are means with their standard errors of the means for five hamsters)

\begin{tabular}{|c|c|c|c|c|}
\hline \multirow[t]{2}{*}{ Experimental group... } & \multicolumn{2}{|c|}{$\mathrm{C}$} & \multicolumn{2}{|c|}{$\mathbf{L}$} \\
\hline & Mean & $\mathrm{SE}$ & Mean & SE \\
\hline Liver & 15540 & 2470 & $514040^{* * *}$ & 79180 \\
\hline Small intestine & 185500 & 20870 & $267900^{* *}$ & 15160 \\
\hline Caecum & 6600 & 1500 & 15450 & 2620 \\
\hline Colon & 10350 & 6360 & 19790 & 5770 \\
\hline Kidneys & 42530 & 10050 & 67830 & 13940 \\
\hline Adrenals & 2180 & 400 & 2320 & 280 \\
\hline Spleen & 710 & 110 & $3830^{* *}$ & 630 \\
\hline
\end{tabular}

Mean values were significantly different from those for group $C$ (Student's $t$ test): ** $P<0.01,{ }^{* * *} P<0.001$.

$\dagger$ For details of dietary regimen and experimental procedures, see p. 480 and pp. 481-482.

Table 6. Molar percentage of cholesterol, phospholipids and bile acids in hepatic bile, total lipid concentration and lithogenic index of control $(C)$ and lithiasic $(L)$ hamsters $\dagger$

(Values are means with their standard errors of the means for five hamsters)

\begin{tabular}{|c|c|c|c|c|}
\hline \multirow[t]{2}{*}{ Experimental group... } & \multicolumn{2}{|c|}{$\mathrm{C}$} & \multicolumn{2}{|c|}{$\mathrm{L}$} \\
\hline & Mean & $\mathrm{SE}$ & Mean & SE \\
\hline Cholesterol & $7 \cdot 2$ & 0.4 & $16 \cdot 3^{* *}$ & $1 \cdot 7$ \\
\hline Phospholipids & $23 \cdot 9$ & $1 \cdot 1$ & 18.5 & $2 \cdot 8$ \\
\hline Bile acids & $68 \cdot 9$ & $1 \cdot 1$ & $65 \cdot 2$ & 1.7 \\
\hline Total lipids $(\mu \mathrm{mol} / \mathrm{ml})$ & $18 \cdot 0$ & $0 \cdot 3$ & 17.8 & 0.6 \\
\hline Lithogenic index & 0.7 & $0 \cdot 1$ & $1.7 * *$ & $0 \cdot 2$ \\
\hline Lithogenic index $\S$ & $1 \cdot 5$ & $0 \cdot 1$ & $4 * *$ & 0.6 \\
\hline
\end{tabular}

Mean values were significantly different from those for group $C$ (Student's $t$ test): ${ }^{* *} P<0 \cdot 01$.

$\uparrow$ For details of dietary regimen, see p. 480 .

$\$$ Lithogenic index determined by the method of Thomas \& Hofmann (1973).

$\$$ Lithogenic index determined by the method of Carey (1978).

Table 7. Specific activity of cholesterol in plasma, liver, bile and gallstones and of cholic acid in bile of control $(C)$ and lithiasic $(L)$ hamsters $†$

(Values are means with their standard errors of the means for five hamsters)

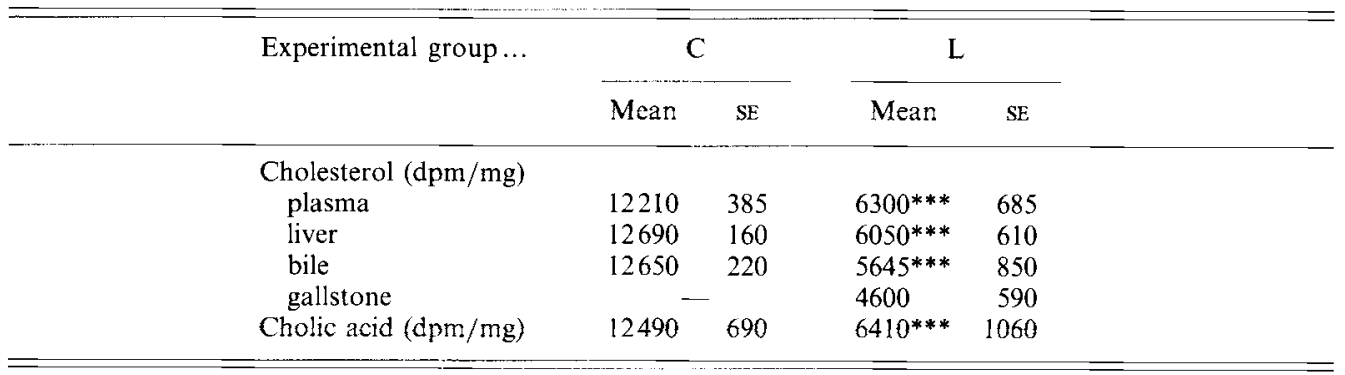

$\mathrm{dpm}$, Disintegrations/min.

Mean values were significantly different from those for group $\mathrm{C}$ (Student's $t$ test): $* * * P<0.001$.

$\dagger$ For details of dietary regimen, see p. 480 . 
Table 8. Bile acid content in $\mu \mathrm{mol} / \mathrm{kg}$ body-weight in gall bladder, small intestine, caecum and colon and bile acids pool of control $(C)$ and lithiasic $(L)$ hamsters $\dagger$

(Values are means with their standard errors of the means for five hamsters)

\begin{tabular}{|c|c|c|c|c|}
\hline \multirow[t]{2}{*}{ Experimental group... } & \multicolumn{2}{|c|}{$\mathrm{C}$} & \multicolumn{2}{|c|}{$\mathrm{L}$} \\
\hline & Mean & $\mathrm{SE}$ & Mean & $\mathrm{SE}$ \\
\hline Gall bladder & 9 & 2 & 6 & 2 \\
\hline Small intestine & 120 & 10 & 70 & $5^{* *}$ \\
\hline Caecum and colon & 109 & 7 & 125 & 9 \\
\hline Pool & 238 & 9 & 201 & $9^{* *}$ \\
\hline
\end{tabular}

Mean values were significantly different from those for group $\mathrm{C}$ (Student's $t$ test): ** $P<0.01$.

$\dagger$ For details of dietary regimen, see p. 480 .

groups. According to the method of Thomas \& Hofmann (1973), the hepatic bile was saturated with cholesterol in group L animals. Lithogenic index was twofold higher in lithiasic hamsters than in the controls. However, according to the method of Carey (1978), the lithogenic index of the bile was higher than 1 in group $C$. In the present case, the lithogenic index of the bile was also twofold higher in group $\mathrm{L}$ than in group $\mathrm{C}$.

\section{Origin of biliary and gallstone cholesterol}

The specific activity of cholesterol was measured in the liver, plasma, bile and gallstones (Table 7) to determine whether cholelithiasis modified specific activities of cholesterol in bile and in gallstones and of cholic acid in bile. In each group of hamsters, the specific activities of cholesterol and cholic acid at the isotopic equilibrium were of the same order. Moreover, in control hamsters, the specific activities of cholesterol in liver, plasma and bile and the specific activity of cholic acid in bile were twice those found in lithiasic hamsters.

\section{Content and composition of bile acids in gastrointestinal tract}

The bile acid content in the gall bladder was not different between the two groups but in lithiasic animals compared with control animals cholic acid increased and conversely chenodeoxycholic acid decreased significantly. In the small intestine, bile acid content decreased in the lithiasic hamster but bile acid composition was not significantly changed. Bile acid content in the caecum and colon did not differ between lithiasic and control hamsters. Thus, the bile acid pool of lithiasic hamsters was significantly lower than that of controls. In faeces, ketonic bile acids were increased in group L compared with group C.

\section{DISCUSSION}

The development of gallstones in hamsters fed on a fat-free diet was higher $(100 \%)$ in the present study than that reported by others (25-80\%) (Ginsberg et al. 1977; Singhal et al. 1984). In contrast with the observations of Dam (1969) and Singhal et al. (1984), all animals were healthy at the end of the experiment and no death or diarrhoea were recorded. This discrepancy might be linked to the strain of hamster used in the present work. Indeed, Singhal et al. (1983a) have shown large differences in cholesterol metabolism between Lakeview and Bio hamster strains.

After 7 weeks of experiment, the growth of control and lithiasic hamsters was very similar. The isotope dilution of plasma cholesterol was constant and the input and output of cholesterol from the body of the hamster (cholesterol system) were nearly at the same level. Thus, the cholesterol system in the two groups of hamsters was in a steady state as 
Table 9. Composition of bile acids in gall bladder, small intestine and faeces of control $(C)$ and lithiasic $(L)$ hamsters $\dagger$

(Values are means with their standard errors of the means for five hamsters)

\begin{tabular}{|c|c|c|c|c|c|c|}
\hline \multirow[b]{2}{*}{$(\%)$} & \multicolumn{2}{|c|}{ Gall bladder } & \multicolumn{2}{|c|}{ Small intestine } & \multicolumn{2}{|c|}{ Faeces } \\
\hline & $\mathrm{C}$ & $\mathrm{L}$ & $\mathrm{C}$ & L & $\mathrm{C}$ & L \\
\hline Isolithocholic & - & - & - & - & $\begin{array}{l}7.8 \\
0.4\end{array}$ & $\begin{array}{l}5 \cdot 5 \\
1 \cdot 1\end{array}$ \\
\hline Lithocholic & $\begin{array}{l}2 \cdot 1 \\
0 \cdot 4\end{array}$ & $\begin{array}{l}0.5 \\
0.3\end{array}$ & $\begin{array}{l}2 \cdot 3 \\
0.5\end{array}$ & $\begin{array}{l}1.7 \\
0.5\end{array}$ & $\begin{array}{r}37.8 \\
2.6\end{array}$ & $\begin{array}{r}30 \cdot 7 \\
3.5\end{array}$ \\
\hline Deoxycholic & $\begin{array}{r}10 \cdot 1 \\
2 \cdot 2\end{array}$ & $\begin{array}{l}9 \cdot 7 \\
2 \cdot 6\end{array}$ & $\begin{array}{l}6.7 \\
0.6\end{array}$ & $\begin{array}{l}5 \cdot 2 \\
1 \cdot 2\end{array}$ & $\begin{array}{r}27.6 \\
3.9\end{array}$ & $\begin{array}{r}21.6 \\
3.9\end{array}$ \\
\hline Cholic & $\begin{array}{r}48.0 \\
3.2\end{array}$ & $\begin{array}{c}70 \cdot 0^{*} \\
9 \cdot 4\end{array}$ & $\begin{array}{r}55 \cdot 6 \\
3 \cdot 3\end{array}$ & $\begin{array}{c}60 \cdot 0 \\
4 \cdot 0\end{array}$ & - & - \\
\hline Chenodeoxycholic & $\begin{array}{r}40 \cdot 4 \\
2 \cdot 8\end{array}$ & $\begin{array}{c}19 \cdot 6^{*} \\
8 \cdot 0\end{array}$ & $\begin{array}{r}35 \cdot 3 \\
2 \cdot 6\end{array}$ & $\begin{array}{r}33 \cdot 2 \\
4 \cdot 2\end{array}$ & - & - \\
\hline Ketones & $-\cdots$ & - & - & - & $\begin{array}{r}26 \cdot 8 \\
2 \cdot 9\end{array}$ & $\begin{array}{c}42 \cdot 3^{*} \\
3 \cdot 9\end{array}$ \\
\hline
\end{tabular}

Mean values were significantly different from those for group $C$ (Student's $t$ test): ${ }^{*} P<0.05$.

$\dagger$ For details of dietary regimen, see p. 480 .

previously in young rats (Chevallier, 1964) and young hamsters (Singhal et al. 1983b). These findings, according to Lutton \& Chevallier (1972), validate the use of this method in the young hamster. Thus, the biodynamics of cholesterol in the lithiasic hamster were characterized by an increase in cholesterol synthesis and simultaneously by a decrease in intestinal cholesterol absorption. The increase in cholesterol input was compensated by an elevation in faecal cholesterol excretion. Bile acid biosynthesis was not modified in this animal.

The decrease in intestinal cholesterol absorption in the lithiasic hamster was associated with a decrease in bile acid content in the small intestine $(-42 \%)$ and in bile acid pool $(-16 \%)$. In hamsters fed on a fat-free diet compared with those fed on a plain pellet diet, Turley \& Spady (1983) did not show any change in the bile acid pool but they had not measured bile acid content in the small intestine. In the rat, the decrease in bile acid content in the small bowel lowered intestinal cholesterol absorption while an interruption of bile acid circulation abolished it completely (Lutton et al. 1973). In the hamster, the nature of bile acids may also be involved in cholesterol absorption. Indeed, in this animal receiving different bile acids in their diets, dihydroxylated bile acids diminished cholesterol absorption while trihydroxylated bile acids had no effect (Singhal et al. 1983 b). In our experiment, the absence of a modification of bile acid composition in the small intestine suggests that the decrease in cholesterol absorption could be explained, in part, by a diminution of bile acid content in this organ. Moreover, the lack of fatty acids in the lithogenic diet modified the composition of biliary phospholipids (Kubota et al. 1981) and probably, the nature of triacylglycerols and fatty acids in the bile as well as the composition of biliary lipids entering the duodenum. These changes could also impair micellar and vesicular solubilization of cholesterol in the small intestine and probably enterocyte membrane permeability to cholesterol. This point warrants further investigation.

Cholelithiasis was also associated with an increase in total cholesterol synthesis (internal and external secretions). The external secretion (cholesterol synthesized in the gastrointestinal tract and poured directly into the intestinal lumen) was similar in lithiasic and 
control animals and represented $9.5 \%$ of total cholesterol synthesis. It also represented respectively 14 and $13 \%$ of faecal cholesterol output in control and lithiasic hamsters. These amounts were similar to those observed in normal man (Férézou et al. 1981) but were lower than those reported in the rat receiving a semi-synthetic diet (Sérougne \& Lutton, 1982). Consequently, the increase in cholesterol synthesis in the lithiasic hamster was associated with an elevation of the internal secretion (cholesterol synthesized in organs and poured into the plasma). The incorporation of $\left(1-{ }^{14} \mathrm{C}\right]$ acetate in digitonin-precipitable sterols of various organs revealed the respective contribution of these organs to synthesis (Lutton et al. 1989). The lithiasic hamster showed a dramatic increase in hepatic cholesterol synthesis but relatively little change in the extrahepatic tissues, except small bowel where an increase also occurred. Overall, in contrast to the controls in which the intestine appeared to be the main organ involved in cholesterol synthesis, the increase in total body sterol synthesis in the lithiasic hamster was mainly associated with an elevation in hepatic cholesterogenesis. This result was also corroborated by the measurement of hepatic activity of HMG-CoA reductase which was found to be five times higher in the lithiasic hamster than in the controls. Similar observations were reported in the lithiasic hamster by Ginsberg et al. (1977) and Turley \& Spady (1983) and in man by Key et al. (1980). However, these observations did not report how this hepatic synthesis was stimulated. In the rat, Chevallier \& Lutton (1973) showed a negative correlation between internal secretion and the cholesterol absorption coefficient. In addition, Wilson (1972) showed that there was an inverse quantitative relationship between the amount of dietary cholesterol absorbed and the rate of de novo cholesterol synthesis in the liver of the baboon (Papio sp). In the rat, Nervi et al. (1975) reported a feedback inhibition of cholesterol synthesis in the liver after intravenous injection of intestinal lipoprotein, particles transporting absorbed cholesterol. Inversely, obstruction of the lymphatic duct induced an increase in the rate of cholesterol synthesis (Weis \& Dietschy, 1969). In the lithiasic hamster compared with the control hamster, a decrease in cholesterol concentration $(-40 \%)$ in the chylomicron and very-low-density lipoprotein has also been observed (Khallou, 1989). Thus, these observations suggest that the marked increase in hepatic cholesterol synthesis in the lithiasic hamster might be partly explained by a decrease in intestinal cholesterol absorption and a lower input of dietary cholesterol to the liver via intestinal lipoproteins.

In contrast to cholesterol synthesis, bile acid biosynthesis in the lithiasic hamster was similar to that of control animals. Indeed, expressed as a percentage of the cholesterol input, transformation of cholesterol into bile acids represented only 35 in the lithiasic group v. 52 in the controls. Generally, changes in the rate of bile acid biosynthesis are parallel to the change in the rate of hepatic cholesterol synthesis (Bjorkhem, 1985). However, in some cases there is a dissociation between cholesterogenesis and cholesterol $7 \alpha$-hydroxylase (cholesterol $7 \alpha$-monooxygenase; EC 1.14.13.17) activity in liver microsomes (Myant \& Mitropoulos, 1977; Bjorkhem, 1986). Our findings support these observations and suggest that hepatic cholesterol synthesis and bile acid biosynthesis are not coupled in the lithiasic hamster.

The changes in relative biliary lipid values in the lithiasic hamster involved an increase in molar percentage of biliary cholesterol with no change in that of total bile acids and phospholipids. Thus, the lithogenic index was markedly increased in this animal. This result agrees with those obtained by Ginsberg et al. (1977) and Singhal et al. (1984). The lithogenic index values calculated from the method of Carey (1978) were twice as high as those calculated from the formula of Thomas \& Hofmann (1973) and data of Admirand \& Small (1968). Similar differences were reported by Ozben (1989) between the lithogenic index values calculated by this latest method and those derived from data of Holzbach et al. (1973). Because this index, according to Carey (1978), takes into account the total lipid 
concentration of the bile sample it is thought to be a better index for cholesterol saturation than that according to Thomas \& Hofmann (1973). In spite of this claim, the index according to Carey (1978) takes into account only cholesterol solubilization in mixed micelles and ignores vesicular cholesterol solubilization which is so important in dilute biles. Therefore, this index is much higher at low than at high total lipid concentration (Van Erpecum et al. 1990).

The bile acid composition in the gall bladder was modified in lithiasic hamsters. The decrease in the proportion of chenodeoxycholic acid in this animal might induce cholesterol crystallization in the gall bladder. In man, chronic ingestion of chenodeoxycholic acid markedly increases the biliary concentration of this bile acid and induces dissolution of gallstones (Thistle \& Hofmann, 1973). In vitro this bile acid has a higher capacity to solubilize cholesterol than cholic acid (Montet et al. 1979). However, in the lithiasic hamster Ginsberg et al. (1977) observed a twofold increase in the biliary concentration of chenodeoxycholic acid and no disappearance of gallstones. These findings suggest that moderate changes in biliary bile acid composition may not affect cholesterol solubilization.

Cholesterol secreted in bile could come from two different sources: (1) newly-synthesized cholesterol in the hepatocytes, (2) plasma cholesterol taken up by specific and non-specific pathways. If the first source has a high contribution to biliary cholesterol secretion and if newly-formed cholesterol is not rapidly exchangeable with plasma cholesterol, then the specific activity of biliary cholesterol at the isotopic equilibrium would be lower than that of plasma cholesterol; on the other hand, if newly synthesized cholesterol is rapidly exchanged with plasma cholesterol, it would be similar. In the present work, cholesterol secreted in the bile of lithiasic or control hamsters had a similar specific activity to that observed in the liver and plasma. These results suggest that in spite of a high hepatic cholesterogenesis in the lithiasic hamster, there is no preferential secretion of cholesterol synthesized de novo into bile. These observations agree with those obtained in the rat and in man (Chevallier \& Rodrigues-Branco, 1963; Férézou et al. 1987) in our laboratory. Cholesterol in gallstones had the same origin. The lower specific activity of gallstones $(-25 \%)$ observed in the lithiasic hamster compared with that of plasma and liver is explained by the rapid development of stones in this species. Indeed, the stones appear to be formed as early as the 3 rd week of the experiment while plasma cholesterol specific activity reached its plateau at the 5 th week. Thus, stones were formed before the cholesterol isotopic equilibrium was well established.

In conclusion, cholelithiasis in the hamster is associated with an increase in hepatic and, to some extent, intestinal cholesterogenesis. This increase was related to a fall in cholesterol absorption which was associated with a lower bile acid content in the small bowel, Despite marked stimulation in hepatic cholesterogenesis, bile acid biosynthesis is not modified in the lithiasic hamster and appears to be 'limited'. Thus, liver cholesterol synthesis and bile acid biosynthesis are dissociated in this animal. This produces an imbalance between bile components, i.e. secretion of high level of cholesterol in bile whereas those of phospholipids and bile acids were normal, and consequently, cholesterol gallstones were formed in the bile. The cholesterol of bile and of gallstones in lithiasic as well as control hamsters is derived from a rapidly exchangeable hepatic pool in equilibrium with plasma.

This investigation was supported by a CRE grant awarded by INSERM and Caisse Régionale d'Assurance Maladie de l'Île de France.

REFERENCES

Admirand \& Small (1985). The physicochemical basis of cholesterol gallstone formation in man. Journal of Clinical Investigation 47, 1043-1052. 
Alberts, A. W. Chen, J., Kuron, G., Hunt, V., Huff, J., Hoffman, C., Rothroch, J., Lopez, M., Joshua, H., Harris, E., Patchett, A., Monaghan, R., Currie, S., Stapley, E., Alberts-Schonberg, G., Hensens, O., Hirshfield, J., Hoogsteen, K., Liesch, J. \& Springer, J. (1980). Mevinolin: a highly potent competitive inhibitor of hydroxymethylglutaryl-coenzyme A reductase and a cholesterol-lowering agent. Proceedings of the National Academy of Sciences, U.S.A. 77, 3957-3961.

Alvaro, M., Angelico, M., Angelico, F., Antonini, R., Mazzarella, B., Bracci, F., Ginanni, S., Corradini, S. \& Attili, A. F. (1985). Plasma lipoproteins in gallstone patients. Relationship to biliary lipid composition. In Recent Advances in Bile Acid Research, pp. 223-224 [L. Barbara, R. H. Dowling, A. L. Hofmann and E. Roda, editors]. New York: Raven Press.

Bjorkhem, I. (1985). Mechanism of bile acid biosynthesis in mammalian liver. In New Comprehensive Biochemistry, pp. 231-278 [H. Danielsson and J. Sjövall, editors]. Amsterdam: Elsevier.

Bjorkhem, I. (1986). Effects of mevinolin in rat liver: evidence for a lack of coupling between synthesis of hydroxy methylglutaryl-CoA-reductase and cholesterol $7 \alpha$ hydroxylase activity. Biochimica et Biophysica Acta 877, $43-49$.

Carey, M. C. (1978). Critical tables for calculating the cholesterol saturation of native bile. Journal of Lipid Research 19, 945-955.

Chevallier, F. (1964). Transferts et synthèse due cholestérol chez le rat au cours de sa croissance (Transfer and synthesis of cholesterol in rats during their growth.) Biochimica et Biophysica Acta 84, 316 -339.

Chevallier, F. \& Giraud, F. (1966). Renouvellement par transfert du cholestérol chez les rats adultes et en croissance (Cholesterol renewal by transfer in growing and adult rats.) Bulletin de la Société de Chimie Biologique 48, 787 801 .

Chevallier, F. \& Lutton, C. (1966). Vitesses des processus de renouvellement du cholestérol contenu dans son espace de transfert chez le rat. I. Méthode et résultats obtenus dans le cas d'un régime semi-synthétique témoin (Rates of cholesterol turnover processes in the transfer space of rat. I. Method and results obtained with a semipurified diet.) Bulletin de la Société de Chimie Biologique 48, 507-523.

Chevallier, F. \& Lutton, C. (1973). The intestine is the major site of cholesterol synthesis in the rat. Nature 242 , $61-62$.

Chevallier, F. \& Rodrigues-Branco, J. (1963). Synthèse du cholestérol hépatique à partir d'acétate $l^{14} \mathrm{C}$ chez les rats normaux et porteurs de fistule biliaire. Origine du cholestérol biliaire (Hepatic cholesterol synthesis determined by the use of $\left[1-{ }^{14} \mathrm{C}\right]$ Acetate in the normal and bile-diverted rats. Origin of biliary cholesterol.) Revue Française d Etudes Cliniques et Biologiques 8, 903-909.

Dam, H. (1969). Nutritional aspects of gallstone formation with particular reference to alimentary production of gallstones in laboratory animals. World Review of Nutrition and Dietetics 11, 199-239.

Einarsson, K., Angelin, B., Ewerth, S., Niesell, K. \& Bjorkhem, I. (1986). Bile acid synthesis in man: assay of hepatic microsomal cholesterol $7 \alpha$-hydroxylase activity by isotope dilution-mass spectrometry. Journal of Lipid Research 27, 82-88.

Férézou, J., Coste, T. \& Chevallier, F. (1981). Origin of neutral sterols in human feces studied by stable isotope labeling ( $\mathrm{D}$ and ${ }^{13} \mathrm{C}$ ). Existence of an external secretion of cholesterol. Digestion 21, 232-243.

Férézou, J., Huc, D., Coste, T., Rautureau, J. \& Lutton, C. (1987). Origine du cholestérol biliaire chez l'Homme (Origin of biliary cholesterol in man.) Gastroentérologie Clinique et Biologique 11, 811-812.

Ginsberg, R. L., Duane, W. K. \& Flock, E. V. (1977). Hepatic-3-hydroxy-3-methyl glutaryl CoA reductase activity in hamsters on a lithogenic diet. Journal of Laboratory and Clinical Medicine 89, 928-936.

Grundy, S. M., Ahrens, E. H. \& Miettinen, T. A. (1965). Quantitative isolation and gas liquid chromatography analysis of total fecal bile acids. Journal of Lipid Research 6, 397-410.

Gurantz, D., Laker, M.F. \& Hofmann, A. F. (1981). Enzymatic measurement of choline-containing phospholipids in bile. Journal of Lipid Research 22, 373-376.

Holzbach, R. T., Marsh, M., Olszewski, M. \& Holan, K. (1973). Cholesterol solubility in bile. Evidence that supersaturated bile is frequent in healthy man. Journal of Clinical Investigation 52, 1467-1479.

Key, P. H., Bonorris, G. G., Marks, J. W., Chung, A. \& Schoenfield, L. (1980). Biliary lipid synthesis and secretion in gallstone patients before and during treatment with chenodeoxycholic acid. Journal of Laboratory and Clinical Medicine 95, 816-826.

Khallou, J. (1989). Biodynamique du cholestérol chez le hamster lithiasique. Influence d'un amidon riche en amylose (Biodynamics of cholesterol in the lithiasic hamster. Influence of an amylomaize starch.) Thèse d'Université, Paris XI.

Kubota, S., Kajiyama, G., Sasaki, H., Horiuchi, I. \& Myoshi, A. (1981). Lipid metabolism in the development of cholesterol gallstone in hamster. IV. The effect of essential phospholipids and plant sterols on the biliary lipids. Hiroshima Journal of Medicine and Science 30, 300-309.

Lutton, C. (1990). Dynamique du cholestérol et des acides biliaires. Aspects comparatifs (Cholesterol and bile acid dynamics: comparative aspects.) Reproduction Nutrition Développement 30, 145-160.

Lutton, C., \& Chevallier, F. (1972). Vitesses des processus de renouvellement du cholestérol contenu dans son espace de transfest, chez le rat. III. Modifications et étude critique de la méthode d'équilibre isotopique (Rates of cholesterol turnover processes in the transfer space of rat: III. Modifications and critical study of the isotopic equilibrium method.) Biochimica et Biophysica Acta 255, 762-779.

Lutton, C., Férézou, J., Sérougne, C., Verneau, C., Champarnaud, G., Magot, T., Mathé, D. \& Sulpice, J. C. 
(1989). Critical analysis of the use of ${ }^{14} \mathrm{C}$-acetate for measuring in vivo rat cholesterol synthesis. Reproduction Nutrition Développement 30, 71-84.

Lutton, C., Mathé, D. \& Chevallier, F. (1973). Vitesses des processus de renouvellement du cholestérol contenu dans son espace de transfert, chez le rat. VI. Influence de la ligature du cholédoque et de l'ingestion d'acides biliaires ou de cholestyramine (Rates of cholesterol turnover processes in the transfer space of rat. VI. Influence of bile duct ligation and ingestion of bile acid or cholestyramine.) Biochimica et Biophysica Acta 306, $483-496$.

Mathé, D. \& Lutton, C. (1984). Le cholestérol. Aspects dynamiques et métaboliques (Cholesterol: dynamics and metabolic aspects.) Journal de Physiologie 79, 41-97.

Montet, J. C., Reynier, M. O., Montet, A. M. \& Gerolami, A. (1979). Distinct effects of three bile salts on cholesterol solubilization by oleate-monoolein-bile salt micelles. Biochimica et Biophysica Acta 575, $289-294$.

Myant, N. B. \& Mitropoulos, K. A. (1977). Cholesterol 7a-hydroxylase. Journal of Lipid Research 18, 135-145.

Nervi, F. O., Weis, H. G. \& Dietschy, J. M. (1975). The kinetics characteristics of inhibition of hepatic cholesterogenesis by lipoproteins of intestinal origin. Journal of Biological Chemistry 250, 4145-4151.

Ozben, T. (1989). Biliary lipid composition and gallstone formation in rabbits fed on soy protein, cholesterol, casein and modified casein. Biochemical Journal 263, 293-296.

Reuben, A., Maton, P. N., Murphy, G. M. \& Dowling, R. H. (1985). Bile lipid secretion in obese and non obese individuals with and without gallstones. Clinical Science 69, 71-79.

Robins, S. J. \& Fasulo, J. (1973). Mechanisms of lithogenic bile production. Studies in the hamster fed an essential fatty acid deficient diet. Gastroenterology 65, 104-114.

Roda, A., Feste, D., Sama, L., Mazella, G., Aldini, R., Roda, E. \& Barbara, L. (1975). Enzymatic determination of cholesterol in bile. Clinica Chimica Acta 64, 337-341.

Rodwell, U. W., Nordrom, J. M. \& Mitschelen, J. J. (1976). Regulation of HMG CoA reductase. Advances in Lipid Research 14, 1-74.

Rukaj, A. \& Sérougne, C. (1983). Effect of excess dietary cystine on the biodynamics of cholesterol in the rat. Biochimica et Biophysica Acta 753, 1-5.

Salen, G., Nicolau, G., Shefer, S. \& Mosbach, E. H. (1975). Hepatic cholesterol metabolism in patients with gallstones. Gastroenterology 69, 676-684.

Sérougne, C. \& Lutton, C. (1982). Répartition du cholestérol d'origine plasmatique dans la villosité intestinale chez le rat (Plasma cholesterol distribution in the intestinal villus of the rat.) Journal de Physiologie 78, 170-174.

Singhal, A. K., Ayengar, N. K. N., May, P. S., McSherry, C. K. \& Mosbach, E. H. (1983a). Cholesterol metabolism in two strains of hamsters. In Dietary Fats and Health, pp. 267-277. Champaign: American Oil Chemist's Society.

Singhal, A. K., Cohen, B. I., Finver-Sadowsky, J., McSherry, C. K. \& Mosbach, E. H. (1984). Role of hydrophilic bile acids and sterols on cholelithiasis in the hamster. Journal of Lipid Research 25, 564-570.

Singhal, A. K., Finver-Sadowsky, J., McSherry, C. K. \& Mosbach, E. H. (1983b). Effect of cholesterol and bile acids on the regulation of cholesterol metabolism in hamster. Biochimica et Biophysica Acta 752, $214-222$.

Thistle, J. L. \& Hofmann, A. F. (1973). Efficacy and specificity of chenodeoxycholic therapy for dissolving gallstones. New England Journal of Medicine 289, 655-659.

Thomas, P. J. \& Hofmann, A. F. (1973). A simple calculation of the lithogenic index of bile: expressing biliary lipid composition on rectangular coordinates. Gastroenterology 65, 698-700.

Turley, S. D. \& Dietschy, J. M. (1978). Re-evaluation of the $3 \alpha$-hydroxysteroid dehydrogenase assay for total bile acids in bile. Journal of Lipid Research 19, 924-929.

Turley, S. D. \& Spady, D. K. (1983). Alteration of the degree of biliary cholesterol saturation in the hamster and rat by manipulation on the pools of preformed and newly synthesized cholesterol. Gastroenterology $\mathbf{8 4}$, 253-264.

Van Erpecum, K. J., Van Berge Henegouwen, G. P., Stoelwinder, B., Schmidt, Y. M. G. \& Willekens, F. L. H (1990). Bile concentration is a key factor for nucleation of cholesterol crystals and cholesterol saturation index in gallbladder bile of gallstone patients. Hepatology 11, 1-6.

Weis, H. J. \& Dietschy, J. M. (1969). Failure of bile acids to control hepatic cholesterogenesis: evidence for the endogenous cholesterol feed-back. Journal of Clinical Investigation 48, 2398-2408.

Wheeler, H. O. (1973). Biliary secretion of bile acids, lecithin and cholesterol in hamsters with gallstones. Gastroenterology 65, 92-103.

Wilson, J. D. (1972). The relation between cholesterol absorption and cholesterol synthesis in the baboon. Journal of Clinical Investigation 51, 1450-1458. 